\title{
Bone mineral density in asthmatic patients treated with inhaled corticosteroids: a case-control study
}

\author{
M. Luengo*, L. del Río**, F. Pons**, C. Picado*
}

Bone mineral density in asthmatic patients treated with inhaled corticosteroids: a casecontrol study. M. Luengo, L. del Río, F. Pons, C. Picado. CERS Journals Ltd 1997. ABSTRACT: Recent studies suggest that inhaled corticosteroids can adversely affect bone metabolism. The objective of this study was to evaluate the importance of these adverse effects in a case-control study.

Bone mineral density (BMD) was measured in 48 asthmatic adults (15 males and 33 females) treated with inhaled steroids (beclomethasone or budesonide) and in 48 gender and age-matched healthy subjects at baseline and at 2 yrs. Vertebral BMD was measured by dual energy $\mathrm{X}$-ray densitometry.

Patients had been treated with a dose of $662 \pm 278 \mu \mathrm{g}$ (range 300-1,000 $\mu \mathrm{g}$ ) of beclomethasone dipropionate or budesonide for more than $1 \mathrm{yr}$ (mean duration of treatment 10.6 yrs, range 1-16 yrs). Twenty four patients had needed 1-6 short courses of oral steroids and seven had received oral corticosteroids (mean daily dose $6.2 \mathrm{mg}$ prednisone) for 2-15 yrs more than 4 yrs prior to the BMD measurements. During the follow-up, 14 patients required 1-3 short courses of oral steroids. There was no correlation either between inhaled corticosteroid doses or duration of treatment and BMD values. There were no significant differences in BMD baseline values between patients and healthy controls. BMD significantly decreased in both groups at 2 yrs, from $1.08 \pm 0.19$ to $1.05 \pm 0.19 \mathrm{~g} \cdot \mathrm{cm}^{-2}(\mathrm{p}=0.002)$ in asthmatics versus $1.12 \pm 0.17$ to $1.09 \pm 0.18{\mathrm{~g} \cdot \mathrm{cm}^{-2}}^{-2}(\mathrm{p}=0.008)$ in controls. There were no significant differences in BMD loss between patients and healthy controls. Furthermore, no differences were found in bone loss when pre- and postmenopausal women were compared with their healthy control counterparts. No differences in baseline BMD were found between patients who had received regular oral corticosteroid therapy or booster courses of oral corticosteroids and those who had not.

Inhaled corticosteroid treatment at a mean dose of $662 \mu \mathrm{g} \cdot \mathrm{day}^{-1}$ and sporadic booster courses of oral corticosteroids do not further increase bone mass loss with respect to that expected from natural bone mass loss.

Eur Respir J 1997; 10: 2110-2113.
*Servei de Pneumologia and **Servei de Medicina Nuclear, Hospital Clinic Universitari, Departament de Medicina, Facultat de Medicina, Barcelona, Spain.

Correspondence: C. Picado

Servei de Pneumologia

Hospital Clinic

Villarroel 170

08036 Barcelona

Spain

Keywords: Bone mineral density bronchial asthma

inhaled steroids

Received: January 291997

Accepted after revision May 281997

Supported in part by grants from Sociedad Española de Neumologia y Cirugia Torácica (SEPAR) and from CIRIT (GRQ 93-9108).
Early introduction of inhaled corticosteroids in the treatment of asthma is advocated by all recently published guidelines on asthma treatment $[1,2]$. These recommendations are based both on the efficacy and lack of systemic side-effects of inhaled corticosteroids.

The potential side-effects of inhaled corticosteroid were initially evaluated by assessing their effect on the hypothalamic-pituitary adrenal axis. In these early studies, inhaled corticosteroids proved to be safe as far as the suppressive effects on the suprarenal function are concerned, even when administered at high doses [3]. The evaluation of adrenal function was made by using plasma cortisol levels, a method with a poor sensitivity. With more sensitive tests, however, the suppressive effects of relatively modest doses of inhaled corticosteroid therapy have been detected $[4,5]$.

Recent studies have also shown that inhaled corticosteroids may have adverse effects on bone metabolism. Two surveys of chronically steroid-dependent asthmatics detected a significant reduction in bone mass in patients treated with inhaled corticosteroids $[6,7]$. Metabolic studies have reported significantly suppressed production of osteocalcin in healthy subjects [8-10] and in asthmatics $[11,12]$. Another parameter of bone metabolism reported to be abnormal in patients treated with inhaled corticosteroids includes serum carboxypropeptide of type I procollagen [11], serum alkaline phosphatase [8], and urinary hydroxyproline [8]. These results were reported in subjects receiving doses of inhaled corticosteroids ranging 800-2,000 $\mu \mathrm{g} \cdot \mathrm{day}^{-1}$. In contrast with these studies, other surveys have failed to demonstrate any detrimental effect of inhaled corticosteroids on bone mass $[13,14]$, or parameters of bone metabolism, such as osteocalcin, procollagen and collagen degradation products, in patients receiving $\leq 800 \mu \mathrm{g} \cdot \mathrm{day}^{-1}[15,16]$.

Most of the studies carried out with inhaled glucocorticoids are short-term or retrospective and, thus, no firm conclusions could be obtained about the actual risk of prolonged inhaled corticosteroid therapy in asthma. Prospective and comparative studies with a control population are needed in order to clarify the role of inhaled corticosteroids on bone metabolism. 


\section{Subjects and methods}

\section{Subjects}

We studied 48 consecutive asthmatic patients (33 females and 15 males), who agreed to take part in the study according to the inclusion criteria. They were taking inhaled corticosteroids at a mean daily dose of $662 \pm$ $278 \mu \mathrm{g}$ (range $300-1,000 \mu \mathrm{g}$ of beclomethasone dipropionate or budesonide) for more than $1 \mathrm{yr}$ (mean duration of treatment $10.6 \mathrm{yrs}$, range 1-16 yrs). Although some patients had received only beclomethasone dipropionate, most of them had used both beclomethasone dipropionate and budesonide at the time the bone mineral density was measured. No attempt was made to compare the effects of both inhaled corticosteroids. Patients were also treated with short- (salbutamol and terbutaline) or long-lasting beta-agonists (salmeterol) by inhalation on an as-needed or regular basis. Twenty four patients had needed short courses of oral corticosteroids (13 received 4-6 short courses and 11 needed 1-3). Ten patients, all female, had received regular oral corticosteroids for periods ranging $2-11$ yrs at a mean daily dose of $6.2 \pm 1.2 \mathrm{mg}$ prednisone. These patients had discontinued regular oral corticosteroid therapy when inhaled corticosteroid therapy was initiated $\geq 4$ yrs prior to their inclusion in the present study.

During the follow-up period of $2 \mathrm{yrs}$, all patients used a spacer device attached to their inhaler. The patients were asked to maintain the same dose of inhaled corticosteroids over the $2 \mathrm{yr}$ follow-up. Patients were monitored to ensure that the inhalation procedure was performed correctly. During the follow-up period, two patients required three short courses of oral corticosteroids, two required two, 10 patients received one, and 31 patients required none. Short courses were usually started with $30 \mathrm{mg}$ of prednisone for 3 days, followed by a progressive reduction of $5 \mathrm{mg}$ every 2 days. Data on oral and inhaled corticosteroid usage was collected by reviewing the clinical records of the two physicians responsible for the care of patients throughout the entire period of inhaled corticosteroid treatment. All patients were fully ambulatory and able to perform their jobs, and none were engaged in vigorous exercise programmes.

The control group was composed of 48 healthy subjects randomly selected from our computerized data bank, consisting of 547 females and 328 males. The 48 subjects selected were matched for age, gender and preor postmenopausal stage with the patients. Subjects engaged in vigorous exercise programmes were excluded.

All the subjects included in the study were nonsmokers. None of the subjects had clinical symptoms or signs suggesting they had a disease that might be responsible for osteoporosis. None of the subjects had taken medications known to cause alterations in bone mineral density, such as vitamin D, calcitonin, diuretics, oestrogens, androgens and anticonvulsants.

The study comprises a cross-sectional survey both of patients and controls and a follow-up of 2 yrs.

The study was approved by the Ethics Committee of our institution and all subjects gave written informed consent to participate.

\section{Bone mineral density}

Bone mineral density (BMD) of the lumbar spine was measured by dual energy X-ray densitometry. BMD values were obtained from the lumbar vertebrae, L2, L3 and $\mathrm{L} 4$, and expressed in terms of $\mathrm{g} \cdot \mathrm{cm}^{-2}$. In all subjects, BMD measurements were taken twice, at baseline and at 2 yrs. The change in bone density was calculated for each subject by subtracting the baseline measurement from the $2 \mathrm{yr}$ measurement. Since the detection of changes in BMD values at $1 \mathrm{yr}$ are usually minor and within the technical variation of the procedure, it was decided not to take this measurement in order to reduce unnecessary radiation.

\section{Statistical analysis}

Differences between BMD values and those recorded at the end of the $2 \mathrm{yr}$ follow-up period were analysed with the two-tailed t-test for paired variables. Differences in BMD values between patients and their healthy control group counterparts were assessed using the twotailed t-test for unpaired variables. The relationship between BMD and corticosteroid treatment was evaluated by using Pearson's correlation. A probability value of 0.05 was considered significant. Results are presented as mean \pm SD.

\section{Results}

The characteristics of the patient and control subject groups are depicted in table 1. Height and weight were not different in patients and healthy subjects. Baseline BMD values and changes at 2 yrs are presented in table 2. There was no significant difference in basal BMD values between patients $\left(1.08 \pm 0.19 \mathrm{~g} \cdot \mathrm{cm}^{-2}\right)$ and healthy controls $\left(1.12 \pm 0.17 \mathrm{~g} \cdot \mathrm{cm}^{-2}\right)$. No differences were detected in baseline BMD values when male and female patients were separately compared with their control counterparts.

BMD significantly decreased both in asthmatics $(\mathrm{p}=$ $0.002)$ and controls $(p=0.008)$ at 2 yrs. However, there were no significant differences in BMD loss between

Table 1. - Demographic data of the study population

\begin{tabular}{lcc}
\hline & $\begin{array}{c}\text { Study } \\
\text { group }\end{array}$ & $\begin{array}{c}\text { Control } \\
\text { group }\end{array}$ \\
\hline Subjects n & 48 & 48 \\
Age yrs & $56 \pm 11$ & $55 \pm 12$ \\
Sex M/F & $15 / 33$ & $15 / 33$ \\
Pre/postmenopausal ratio & $11 / 22$ & $11 / 22$ \\
Weight kg & $64 \pm 10$ & $64 \pm 10$ \\
Height cm & $160 \pm 7$ & $160 \pm 8$ \\
Inhaled steroid dosage $\mu \mathrm{g} \cdot \mathrm{day}^{-1}$ & $662 \pm 278$ & - \\
Duration of steroid treatment yrs & $10.6 \pm 12.9$ & - \\
FEV1 \% pred & $70 \pm 18$ & - \\
FVC \% pred & $85 \pm 14$ & - \\
Baseline BMD g.cm ${ }^{-1}$ & $1.08 \pm 0.19$ & $1.12 \pm 0.17$ \\
\hline
\end{tabular}

Data are presented as absolute value or mean \pm SD. M: male; F: female; FEV1: forced expiratory volume in one second; FVC: forced vital capacity; $\%$ pred: percentage of predicted value; BMD: bone mineral density. 
Table 2. - Baseline bone mineral density and changes at 2 yrs

\begin{tabular}{lccccccc}
\hline & \multicolumn{5}{c}{ Study group } & & \multicolumn{3}{c}{ Control group } \\
\cline { 2 - 4 } & Baseline & 2 yrs & p-value & & Baseline & 2 yrs & p-value \\
\hline All subjects & $1.08 \pm 0.19$ & $1.05 \pm 0.19$ & 0.002 & & $1.12 \pm 0.17$ & $1.09 \pm 0.18$ & 0.008 \\
Male & $1.15 \pm 0.12$ & $1.14 \pm 0.12$ & NS & & $1.16 \pm 0.20$ & $1.15 \pm 0.20$ & NS \\
Female & $1.05 \pm 0.20$ & $1.02 \pm 0.19$ & 0.002 & & $1.10 \pm 0.16$ & $1.07 \pm 0.16$ & 0.013 \\
Premenopausal & $1.19 \pm 0.13$ & $1.15 \pm 0.12$ & NS & & $1.16 \pm 0.08$ & $1.12 \pm 0.12$ & NS \\
Postmenopausal & $0.98 \pm 0.20$ & $0.95 \pm 0.20$ & 0.008 & & $1.07 \pm 0.18$ & $1.04 \pm 0.17$ & 0.02 \\
\hline
\end{tabular}

Data are presented and mean \pm SD. NS: nonsignificant.

patients and healthy subjects. Changes in BMD were examined separately in males and females. Neither asthmatic noncontrol males showed a significant loss of bone mass. Both female asthmatics $(\mathrm{p}=0.002)$ and female controls ( $\mathrm{p}=0.013$ ) showed a significant loss of bone mass. No significant differences in the magnitude of bone loss were detected between pre- and postmenopausal patients compared with their healthy control counterparts. No correlation was found between inhaled corticosteroid doses or the duration of treatment and BMD values. No differences in the rate of bone loss were found between patients who had received booster courses of oral corticosteroids and those not treated with this therapy. Furthermore, there were no differences found in baseline BMD between the female patients who had received regular oral corticosteroid therapy $(n=10 ; 1.049 \pm 0.119$ $\left.\mathrm{g} \cdot \mathrm{cm}^{-2}\right)$ and those who had not $\left(\mathrm{n}=23 ; 1.052 \pm 0.23 \mathrm{~g} \cdot \mathrm{cm}^{-2}\right)$.

\section{Discussion}

Our results from a cross-sectional study show that patients with asthma treated with a mean daily dose of $662 \pm 278 \mu \mathrm{g}$ of inhaled corticosteroids for a mean of 10.6 yrs have a bone density similar to that of healthy subjects. A prospective study of two additional years also showed that inhaled corticosteroids do not increase the rate of naturally occurring bone loss in healthy people. No deleterious effects of short courses of oral corticosteroids on BMD were seen either in the crosssectional study or the follow-up.

Our results are at variance with two cross-sectional surveys of asthmatic adults receiving inhaled corticosteroid therapy. Both studies reported a reduction in bone mass in comparison with untreated subjects $[6,7]$. These differences may be due to differences in methods and patients, since REID et al. [6] measured calcium content of the whole body, whilst we measured BMD at the spine. Our patients had been treated with a dose of inhaled corticosteroids ranging 300-1,000 $\mu \mathrm{g} \cdot \mathrm{day}^{-1}$, which was much lower than the dose used in the study by PACKE et al. [7] (ranging 1,000-2,000 $\mu \mathrm{g} \cdot \mathrm{day}^{-1}$ ). Surprisingly, in the cross-sectional study by PACKE et al. [7], 1,000-2,000 $\mu \mathrm{g} \cdot \mathrm{day}^{-1}$ of inhaled corticosteroids given for a relatively short period of time (median duration 3 yrs, range 1-7 yrs) apparently exerted the same effect as $7 \mathrm{mg} \cdot \mathrm{day}^{-1}$ of prednisolone plus a high dose of inhaled corticosteroids (the dose of inhaled steroids in these groups was not given). It should be noted that in the study by PACKE $e t$ $a l$. [7] the patients were not adequately matched for gender because the proportion of males was much higher in the inhaled group (55\%) and the oral corticosteroid group $(60 \%)$ than in the control group $(39 \%)$. Neither were the three groups matched for anthropometric factors associated with BMD, such as weight and height [17].

The major criticism of these two studies is the possible effect of past courses of systemic corticosteroids on BMD measurements. However, we could not detect any deleterious effect of this therapy in our patients. Although short courses of corticosteroids increase bone resorption and inhibit bone formation as measured by biochemical markers [18], it is interesting to note that there are no studies demonstrating that this therapy may either increase the rate of bone loss or cause permanent damage to bone architecture. In fact, limited data show that even very large repetitive doses of methylprednisolone given intravenously in patients with rheumatoid arthritis or multiple sclerosis do not cause bone loss $[19,20]$. These findings suggest that, in order to produce bone loss, corticosteroids have to be administered continuously, and that not only is the cumulative dose of corticosteroids important, but also the mode of administration.

We found no significant effect of past oral corticosteroid therapy on BMD in 10 female patients. This was probably due to the fact that our patients had been treated with low doses of oral corticosteroids and also because steroid-induced bone loss is potentially reversible $[21,22]$. Various studies have shown that dosage determines the presence or absence of deleterious effects of oral corticosteroid therapy on bones. Prednisone doses of $\leq 7.5 \mathrm{mg} \cdot \mathrm{day}^{-1}$ do not appear to cause significant bone loss in rheumatoid arthritis [23, 24] and systemic lupus erythematosus [25]. Other studies, however, have found significant bone loss in the initial months of prednisone therapy in rheumatoid arthritis using a mean daily dose of $7.5 \mathrm{mg}$ of prednisone [26]. The possible reversibility of steroid-induced osteoporosis is supported by the rapid rise of mineral density that follows discontinuation of endogenous [20] or exogenous [22, 26] glucocorticoid excess. Bone mineral probably increases even after discontinuation or reduction of oral corticosteroids in patients receiving high doses of inhaled corticosteroids. ToOGOOD et al. [27] have recently reported that, in patients receiving regular oral corticosteroid therapy, BMD improved among those receiving high doses of inhaled corticosteroid. These findings probably reflect the restitution of previously osteopenic bone consequent to the withdrawal of prednisone after commencement of inhaled corticosteroid treatment [27].

In agreement with our results, Boulet et al. [13] and BARALDI et al. [14] have reported that doses ranging from 400 to $>800 \mu \mathrm{g} \cdot \mathrm{day}^{-1}$ of inhaled steroids do not affect BMD in asthmatic adults [13] and children [14]. Both studies were prospective and compared patients on inhaled steroids with a control population of patients not taking inhaled corticosteroids [13] or taking very low doses [14]. In the study by BARALDI et al. [14], however, the population was composed of children, as compared to our adult population, the number of patients 
was very low and the follow-up lasted for only 6 months. Like us, Boulet et al. [13] found no correlation between the duration or dose of corticosteroids used and bone density, even with doses higher than $800 \mu \mathrm{g}$. The lack of effect of inhaled glucocorticoids on BMD contrasts with the demonstrated effect of this therapy on different parameters of bone metabolism in short-term studies in adults [8-12]. It should be noted, however, that in these studies the mean doses of inhaled corticosteroid were higher than the mean dose administered to our patients. Moreover, long-term studies found no evidence of detrimental effects of inhaled corticosteroids on several parameters of bone metabolism (osteocalcin, procollagen and collagen degradation products) $[15,16]$.

Taken together, these results suggest that the potential deleterious effects of inhaled corticosteroids observed in short-term studies, and in those used at high doses, cannot be extrapolated to prolonged treatment with the same drugs with doses below 1,000 $\mu \mathrm{g} \cdot \mathrm{day}^{-1}$. Because most patients suffering from persistent asthma can usually be controlled with $\leq 1,000 \mu \mathrm{g} \cdot \mathrm{day}^{-1}$ of inhaled corticosteroids, the lack of demonstrable effects of long term use of corticosteroids on bone mineral density is reassuring and suggests that at these doses the undesirable effects of inhaled corticosteroids on bone metabolism are nil or insignificant. Our results also suggest that occasional booster courses of oral corticosteroids do not further increase bone mass loss with respect to what is expected from natural bone mass loss.

\section{References}

1. Guidelines for the diagnosis and management of asthma. National Heart, Lung and Blood Institute, National Asthma Education Program Expert Panel Report. J Allergy Clin Immunol 1991; 88 (Suppl.): 425-534.

2. International Asthma Management Project. International Consensus Report on the diagnosis and management of asthma. Clin Exp Allergy 1992; 22 (Suppl. 1): 1-72.

3. Smith MJ, Hodson ME. Effects of long-term inhaled high-dose beclomethasone dipropionate on adrenal function. Thorax 1983; 38: 676-681.

4. Law CM, Marchant JL, Honour JW, Preece MA, Warner JO. Nocturnal adrenal suppression in asthmatic children taking inhaled beclomethasone dipropionate. Lancet 1986; 1: 942-944.

5. Nikolaizik WH, Marchant JL, Preece MA, Warner JO. Nocturnal cortisol secretion in healthy adults before and after inhalation of budesonide. Am J Respir Crit Care Med 1996; 153: 97-101.

6. Reid DM, Nicoll JJ, Smith MA, Higgins B, Tothill P, Nuki G. Corticosteroids and bone mass in asthma: comparisons with rheumatoid arthritis and polymyalgia. $\mathrm{Br}$ Med J 1986; 293: 1463-1465.

7. Packe GE, Douglas JG, McDonald AF, Robins SP, Reid DM. Bone density in asthmatic patients taking high-dose inhaled beclomethasone dipropionate and intermittent systemic corticosteroids. Thorax 1992; 47: 414-417.

8. Ali NJ, Capewell S, Ward MJ. Bone turnover during high-dose inhaled corticosteroid treatment. Thorax 1991; 46: 160-164.

9. Jennings B, Anderson K, Johannsson S. Assessment of systemic effects of inhaled glucocorticosteroids: comparison of the effects of inhaled budesonide and oral prednisolone on adrenal function and markers of bone turnover. Eur J Clin Pharmacol 1991; 40: 77-82.

10. Pow EM, Prummel MF, Oosting H, Roos CM, Endert E. Beclomethasone inhalation decreases serum osteocalcin concentrations. BMJ 1991; 302: 627-628.

11. Sorva R, Turpeinen M, Juntunen-Backman K, Karonen SL, Sorva A. Effects of inhaled budesonide on serum markers of bone metabolism in children with asthma. $J$ Allergy Clin Immunol 1992; 90: 808-815.

12. Kimberg KA, Russel DO, Hopp BA, Biven RE, Gallagher JC. Bone mineral density in normal and asthmatic children. J Allergy Clin Immunol 1994; 94: 490-497.

13. Boulet LPh, Giguère MC, Milot J, Brown J. Effects of long-term use of high-dose inhaled steroids on bone density and calcium metabolism. J Allergy Clin Immunol 1994; 94: 796-803.

14. Baraldi E, Bollini MC, De Marchi A, Zacchello F. Effects of beclomethasone dipropionate on bone mineral content assessed by X-ray densitometry in asthmatic children: a longitudinal evaluation. Eur Respir J 1994; 7: 710-714.

15. Kerstjens HAM, Postma DS, van Doormaal JJ, et al. Effects of short-term and long term treatment with inhaled corticosteroids on bone metabolism in patients with airways obstruction. Thorax 1994; 49: 652-656.

16. Le Bourgeois M, Cormier C, Kindermans C. Inhaled beclomethasone and bone metabolism in young asthmatic children: a six month study. J Allergy Clin Immunol 1995; 96: 565-567.

17. Orwoll ES, Bauer DC, Vogt TM, Fox KM. Axial bone mass in older women. Ann Intern Med 1996; 124: 187-196.

18. Morrison D, Ali NJ, Routledge PA, Capewell S. Bone turnover during short course prednisolone treatment in patients with chronic obstructive airways disease. Thorax 1992; 47: 418-420.

19. Egsmose C, Lund B, Hansen TM. Effect on bone of mega-dose methylprednisolone in rheumatoid arthritis. In: Christiansen C, Johansen JS, Riis BJ, eds. Osteoporosis 1987. Copenhagen, Osteopress, 1987: pp. 1047-1050.

20. van der Wiel HE, Polman CH, Netelebos JC. Corticosteroids and bone mass (Letter). Ann Intern Med 1990; 113: 560 .

21. Lufkin EG, Wahner HW, Bergstralh EJ. Reversibility of steroid-induced osteoporosis. Am J Med 1988; 85: 887-888.

22. Rizzato G, Montemurro L. The reversibilty of exogenous corticosteroid-induced osteoporosis. Bone Mineral 1992; 17 (Suppl. 1): 141.

23. Sambrook PN, Eisman JA, Yeates MG, Pocock NA, Eberl S, Champion GD. Osteoporosis in rheumatoid arthritis: safety of low-dose corticosteroids. Ann Rheum Dis 1986; 45: 950-953.

24. Sambrook PN, Cohen MI, Eisman JA, Pocock NA, Champion GD, Yeates MG. Effects of low-dose corticosteroids on bone mass in rheumatoid arthritis: a longitudinal study. Ann Rheum Dis 1989; 48: 535-538.

25. Pons F, Peris P, Guañabens N, et al. The effects of systemic lupus erythematosus and long-term steroid therapy on bone mass in premenopausal women. Br J Rheumatol 1995; 34: 742-746.

26. Laan RFJM, van Riel PLCM, van Putte LBA, et al. Low-dose prednisone induces rapid reversible axial bone loss in patients with rheumatoid arthritis. Ann Intern Med 1993; 119: 963-968.

27. Toogood JH, Baskerville JC, Markow AE, et al. Bone mineral density and the risk of fracture in patients receiving long-term inhaled steroid therapy for asthma. $J$ Allergy Clin Immunol 1995; 96: 157-166. 